ARTIGOS

DOI https://doi.org/10.31639/rbpfp.v10i18.178

\title{
Pesquisa em formação de professores do Grupo Práxis Educativa Dimensões e Processos: questões teórico-metodológicas
}

Joana Paulin Romanowski (PUC-PR) Pura Lúcia Oliver Martins (PUC-PR) Dilmeire Vosgerou (PUC-PR)

\begin{abstract}
RESUMO: Este artigo apresenta considerações sobre o Grupo de Pesquisa Práxis Educativa: Dimensões e Processos que integra a Linha de Pesquisa Teoria e Prática na Formação de Professores, do Programa de Pós-graduação em Educação da PUC - PR. Esse grupo tem por objeto o estudo da prática educativa realizada na escola. As investigações têm por finalidade compreender as relações da ação docente com as interferências socioculturais no cotidiano dessa prática. O processo de análise toma a prática para, a partir dela, compreender as relações que a orientam. A teoria resultante é expressão dessa prática (MARTNS, 2009, 2016). Os temas focalizados nas pesquisas abordam a didática, a formação e profissionalização do professor (inserção e desenvolvimento profissional), e os saberes docentes.
\end{abstract}

PALAVRAS-CHAVE: Formação de Professores; Pesquisa e Formação; Prática educativa

\section{Research in teacher training in the Práxis Educativa Group Dimensions and Processes: theoretical-methodological questions}

\begin{abstract}
This article presents considerations about the Educational Praxis Research Group: Dimensions and Processes that integrates the Research and Theory and Training in Teacher Training Line of the Graduate Program in Education of the Pontifical Catholic University of Paraná PUC - PR. The purpose of this group is to study the educational practice at school. The aim of the research is to understand the relationship between teacher action and sociocultural interference in the daily life of this practice. The process of analysis takes the practice to understand the relationships that guide it. The resulting theory is an expression of this practice (MARTNS, 2009, 2016). The themes focused on the researches deal with didactics, teacher training and Professionalism (insertion and professional development), and teaching knowledge.
\end{abstract}

KEYWORDS: Teacher Training; Research and Training; Educational practice 


\section{autêntica}

DOI https://doi.org/10.31639/rbpfp.v10i18.178

\section{INTRODUÇÃO ${ }^{1}$}

Este artigo apresenta considerações sobre o Grupo de Pesquisa Práxis Educativa: Dimensões e Processos que integra a Linha de Pesquisa Teoria e Prática na Formação de Professores, do Programa de Pós-graduação em Educação da PUC - PR. Esse grupo tem por objeto o estudo da prática educativa realizada na escola. As investigações têm por finalidade compreender as relações da ação docente com as interferências socioculturais no cotidiano dessa prática. O processo de análise toma a prática para, a partir dela, compreender as relações que a orientam. A teoria resultante é expressão dessa prática (MARTNS, 2009, 2016). Os temas focalizados nas pesquisas abordam a didática, a formação e profissionalização do professor (inserção e desenvolvimento profissional), e os saberes docentes.

O inventário proposto neste artigo se realiza na perspectiva de estado da arte, para compreender os aportes significativos que orientam as investigações, as 'ilhas' de disseminação bem como os limites e lacunas nas quais o grupo se move (MESSINA, 1998). Esse balanço permite a avaliação da produção do grupo de modo a contribuir com a consolidação da pesquisa desenvolvida. Os contributos de Messina (1998) ajudam a situar a perspectiva assumida neste artigo de que ao colocar a pesquisa do grupo em exame estamos fazendo "um estado da arte" visto "como um mapa que nos permite continuar caminhando" (MESSINA, 1998, p.01). Ainda, a autora destaca que "um estado da arte é também uma possibilidade de perceber discursos que em um primeiro exame se apresentam como descontínuos ou contraditórios" (id.ibid), que, contudo, poderá configurar possibilidades de contribuir com a teoria e prática da pesquisa que é examinada.

Salientamos que o Grupo de Pesquisa Práxis Educativa: Dimensões e Processos está aprovado no Programa de Pós-Graduação em Educação e no Conselho Universitário da Pontifícia Universidade Católica do Paraná. Também, está cadastrado desde 1999, no Diretório dos Grupos de Pesquisa do Brasil, Conselho de Desenvolvimento Científico e Tecnológico - CNPO. O registro atende a finalidade de contribuir para fomentar a pesquisa científica e tecnológica, incentivar a formação de pesquisadores brasileiros, e expressar a produção do conhecimento científico. O Diretório dos Grupos de Pesquisa do Brasil mantém informações permanentes por meio de censos com informações que sintetizam a evolução temporal e agregada do perfil dos grupos de pesquisa.

Os assuntos tomados como objeto de estudo pelo grupo se situam no campo da formação de professores e da didática. Roldão (2007) ao se referir a constituição do campo disciplinar da formação de professores na sua composição, estabelece como "campos estruturantes", "campos adjacentes" e "campos próximos". Assim, as pesquisas realizadas se situam no campo estruturante, quando abordam objetos de investigação ai diretamente instalados, e no campo adjacente ao examinar objetos relativos à didática. De todo modo, ao eleger objeto relativos à didática, é neste campo disciplinar que a pesquisa está localizada. Assim, as pesquisas do grupo estabelecem limites tênues entre esses dois campos, contudo cada pesquisa delimita com pertinência o campo em que se insere. Marin, Penna e Rodrigues (2012) ao discutirem a relação entre didática e formação de professores salientam que ao problematizar o trabalho de ensinar dos professores se estabelece relação com a formação de professores. Ressaltam as autoras que a Didática assume a perspectiva formadora ao discutir os processos de ensinar e aprender com a intenção de completar a formação pedagógica dos futuros professores.

1 Este texto é uma versão revista e ampliada da originalmente apresentada no III Simpósio de Grupos de Pesquisa sobre formação de professores do Brasil, 2016. Participaram da primeira versão Marília Marques Mira e Marly Macedo. 


\section{autêntica}

DOI https://doi.org/10.31639/rbpfp.v10i18.178

De outra perspectiva, parte-se do "pressuposto de que as sistematizações teóricas das abordagens distintas das práticas de formação de professores são produzidos socialmente a partir de determinadas circunstâncias históricas e de que tais circunstâncias determinam os tipos de relações sociais que vão forjar as tecnologias utilizadas na relação pedagógica" como propõe Martins (2009). Desse modo, continua a autora dizendo que "a realização da formação de professores, viabilizada por um determinado tipo de organização curricular, está intimamente vinculada às finalidades deste num contexto social mais amplo e expressa a relação social básica no interior do modo de produção capitalista (MARTINS, 2009). Destarte, esses campos - didática e formação de professores - dialogam, se relacionam e transvertem, sem que percam suas especificidades. Ao contrário, as pesquisas aí forjadas podem se constituir em terreno fértil de aperfeiçoamento, aprofundamento e produção profícua na constituição da teoria, uma vez considerada como ponto de partida a prática pedagógica. O exame rigoroso dessa prática consubstancia-se em contributo para ambos os campos. Assim, mais adiante neste texto serão ampliadas estas dimensões, indicando inclusive os aportes teóricos com os quais ponderamos e estabelecemos diálogos epistêmicos.

Ressaltamos que o Grupo Práxis entende a pesquisa como um processo coletivo para favorecer o intercâmbio entre pesquisadores e áreas de conhecimento na perspectiva da interdisciplinaridade de modo a favorecer a colaboração científica, aprofundado a discussão e análise das questões e problemas investigados. Essa prática de realização de pesquisa em parceria favorece uma nova cultura acadêmica, superando o individualismo e caminhando para práticas mais colaborativas (CUNHA, 2014), fundamentais para o desenvolvimento docente (MEYER, VOSGERAU, BORGES, 2018).

Costa (1994) ao discutir o saber como construção coletiva não nega esta possibilidade, ao contrário, reforça, mas alerta para o necessário rigor de tal modo que não se banalize em "jargões despidos de qualquer relevância" (COSTA, 1994, p. 17). Sob essa égide o grupo é formado por pesquisadores, estudantes de graduação e pós-graduação, professores das redes de ensino, mestres e doutores. Define como propósito de que o conhecimento urdido no rigor da crítica pode estabelecer um saber válido de "caráter fundamentalmente laborioso do homem que se constrói historicamente e tem na atividade o movimento central desta construção" como afirma Costa $(1994$, p. 17) ao argumentar sobre as relações dialéticas na pesquisa. Os atuais integrantes do grupo estão listados ao final do texto.

Uma vez indicados esses elementos introdutórios, realçamos que o texto está organizado inicialmente apresentando a trajetória do grupo; em seguida indicando as pesquisas desenvolvidas, a articulação com outros grupos de pesquisa e os aportes teóricos metodológicos que orientam as discussões e análises empreendidas nas pesquisas realizadas. Finaliza com as considerações finais.

\section{TRAJETÓRIA DO GRUPO}

O grupo de pesquisa Práxis Educativa: Dimensões e Processos integra a Linha de Pesquisa Teoria e Prática na Formação de Professores, do Programa de Pós-graduação em Educação da PUC - PR. Inicia sua trajetória em 1995, com a nominação de Grupo de Pesquisa Metodologia do Ensino e Avaliação da Aprendizagem na Educação Superior. Os primeiros resultados do trabalho do grupo foram divulgados no $10^{\circ}$ ENDIPE (Encontro Nacional de Didática e Prática de Ensino), realizado no Rio de Janeiro em maio de 2000.

Uma síntese dos projetos realizados pelo grupo, apresentada a seguir, permite verificar sua trajetória ao longo da década de 2000 a 2010. Em 2001, o projeto de pesquisa abordou a metodologia do ensino e a avaliação da aprendizagem, na Educação Superior. Esse grupo contribuiu para a definição das linhas de pesquisa do 


\section{autêntica}

DOI https://doi.org/10.31639/rbpfp.v10i18.178

Mestrado em Educação da PUCPR. Em 2002, a participação no ENDIPE realizado em Goiânia versou sobre a avaliação da aprendizagem no ensino superior.

Em 2003, as pesquisas realizadas direcionaram-se para a aprendizagem dos alunos em cursos de licenciatura, evidenciando diferenciação dos estilos de aprendizagem. A partir deste projeto, o grupo passa a investigar a formação de professores. Nos ENDIPEs de 2004, realizado em Curitiba, de 2006, em Recife e de 2008, em Porto Alegre, foram divulgados resultados parciais das pesquisas que versam sobre formação de professores. Neste período o grupo organizou dossiê sobre a prática pedagógica publicado na Revista Diálogo educacional e publicou vários artigos sobre o ensino superior e a formação de professores em periódicos como Linhas Críticas, UNB, Avaliação, UNICAMP, livros e capítulos de livros focalizando a didática no ensino superior. Em 2004, foi destacado a pesquisa em formação de professores. Igualmente, nos encontros da ANPEd Sul, vários trabalhos foram apresentados pelos integrantes do grupo referentes à formação de professores, oriundos de pesquisas realizadas pelos membros titulares do grupo, por mestrandos e bolsistas de PIBIC. Em 2004, o grupo incorpora o projeto Princípios e Metodologia na Área da Didática do Ensino Superior, a partir da "Didática Prática", coordenado por Pura Lúcia Oliver Martins.

Em 2005, têm início os projetos: a) Impacto da Pesquisa na Formação de professores. b) Profissionalização dos Egressos do Curso de Pedagogia; ambos coordenados por Joana Paulin Romanowski. Em 2006, estes projetos foram unificados, no projeto denominado Formação e Profissionalização de Professores: Pesquisas e Tendências. Ainda, em 2005, ressalta-se que foi feita a alteração da denominação do grupo para - Práxis educativa: dimensões e processos; a liderança do grupo é alterada passando a ser exercida pelas doutoras Joana Paulin Romanowski e Pura Lúcia Oliver Martins. Lilian Anna Wachowicz passou a integrar o grupo como pesquisadora colaboradora. A renominação resultou de uma ampla discussão no colegiado do programa em que foram avaliados e reprogramados todos os grupos de pesquisa. Em 2006 foram publicados artigos e participações em eventos.

Em 2007, o grupo desenvolveu a pesquisa "As disciplinas pedagógicas nos cursos de licenciatura: tensões e prioridades". Essa pesquisa teve por área de investigação a formação do professor nos cursos de licenciatura associado à pesquisa desenvolvida por Eduardo Terrazan - UFSM. A investigação focalizou as reformulações dos cursos de licenciatura em instituições (universidades) do estado do Paraná.

Os resultados apontam que as instituições, em sua maioria, atenderam as proposições da legislação, sendo que as propostas de organização curricular incluíram as disciplinas e atividades obrigatórias. Verificam-se, nas instituições, que ocorreram mudanças na organização administrativa, instituindo uma coordenação geral dos cursos de Licenciaturas e avanços na constituição de identidade específica para a formação de professores. No período 2007/2009 o grupo obteve apoio do CNPq. Os resultados foram divulgados no XV ENDIPE realizado em Belo Horizonte, 2010 (MARTINS e ROMANOWSKI, 2010); VIII ANPEd Sul, Londrina, 2010, em capítulos de livros e artigos em periódicos.

No período de 2009 a 2015, o grupo desenvolveu dois projetos de pesquisa que focalizam a didática, a prática profissional, o estágio na formação do professor nos cursos de licenciatura e a interlocução desses cursos com a Educação Básica. Constituem um estudo para compreensão do processo de formação para a docência iniciado no projeto de investigação realizado no período 2007 a 2009. Contaram com apoio de pesquisa do $\mathrm{CNPq}$, financimento de projeto e bolsas produtividade em pesquisa. 


\section{autêntica}

DOI https://doi.org/10.31639/rbpfp.v10i18.178

A partir de 2010, passou a integrar o grupo a Profa. Dra. Dilmeire Sant'Anna Ramos Vosgerau com o projeto Cenários Pedagógicos para a Integração das TIC na Formação de Professores - Cri@tividade. Este projeto, tem como foco central a realização de pesquisas sobre os desafios enfrentados pelos professores da educação básica na integração das tecnologias da informação e comunicação (TIC) à prática pedagógica, comporta a concepção de objetos de aprendizagem reutilizáveis, instrumentos de acompanhamentos da aprendizagem, como também os cenários pedagógicos que permitirão a integração dos recursos produzidos à prática do professor.

O grupo participa intensamente dos Gts da ANPED, Gt 08 Formação de Professores e GT 04 Didática. No Gt de formação de professores participa dos Simpósios realizados pelo GT, tendo organizado o II Simpósio de Grupos de Pesquisa sobre Formação de Professores, em 2011. É integrante, também, da Rede Interinstitucional de Pesquisadores em Formação e Prática Docente, composta por grupos de pesquisa da PUCPR, UNIVILLE, UFSC, UTPFR, FURB, UFPel, UEPG, IFSUL, UNINTER. A Rede RIPEFOR realiza periodicamente encontros de pesquisa e, em 2016, o $6^{\circ}$ Encontro foi realizado na FURB, com a temática "Metodologia de Investigação em Formação de Professores. Em 2017 ocorreu o $7^{\circ}$ Encontro com a temática Formação de professores: perspectiva teóricas e metodológicas.

$\mathrm{Na}$ atualidade os projetos realizados pelo grupo direcionam-se para: "Inserção profissional de professores da educação básica: da formação à profissionalização"; "A relação universidade e escola nos cursos de formação de professores", "Cenários Pedagógicos para a Integração das TICS na Formação de Professores - Cri@tividade", "Interlocução da prática pedagógica da educação básica com a universidade no processo de formação docente" e "Inserção Profissional do Professor da Educação Básica: da formação do professor à profissionalização". O projeto Inserção profissional de professores da educação básica se articula a Red de Indución a La Docência/Red de Insercion no ensino, coordenado por Carlos Marcelo, Universidad de Sevilla. Ainda, o grupo está inscrito na ISATT, International Study Association on Teachers and Teaching. O grupo também, por meio da atuação de seus pesquisadores, se articula ao Centre de recherche interuniversitaire sur la formation et la profession enseignante (CRIFPE-Canadá).

Ao discutir as atuais pesquisas do grupo, no próximo item, o texto apresenta seus aportes teórico-metodológicos assumindo a perspectiva de estado da arte. Com efeito, trata-se de discutir as concepções que orientam a produção acadêmica, destacando conceitos, ainda que com caráter inventariante.

\section{APORTES TEÓRICO METODOLÓGICOS: INVENTÁRIO DAS PESQUISAS DO GRUPO}

As pesquisas realizadas pelo grupo abordam problemáticas a respeito da formação inicial, continuada, desenvolvimento profissional de professores, prática docente e tecnologias educacionais, portanto se situam no campo da formação de professores, da didática e das tecnologias educacionais, como indicado neste texto. Em cada projeto de pesquisa é focalizado um objeto de pesquisa relacionado a um desses campos e ou à sua integração. Desta perspectiva, os aportes teóricos que norteiam as investigações se situam nos campos em se originam. Assim os estudos são fundamentados em referenciais que possibilitem análises densas e aprofundadas para "uma produção de conhecimentos novos; uma produção rigorosa de encaminhamentos; uma comunicação de resultados" como propõe Beillerot (1991, p. 19). Além disto, nesta mesma senda, as pesquisas buscam uma perspectiva crítica, sistemática e rigorosa quanto às fontes, metodologia e processo de análise de modo a interpretar e compreender para expressar contribuições válidas e legítimas. (BEILLEROT, 1991, p. 28) O cotejamento permanente das pesquisas realizadas com pesquisas do campo e pelas revisões sistemáticas, pela análise rigorosa suportada por uso de softwares específicos (VOSGERAU; 


\section{autêntica}

DOI https://doi.org/10.31639/rbpfp.v10i18.178

POCRIFKA; SIMONIAN, 2016; VOSGERAU; MEYER; CONTRERAS, 2017), pela discussão com pares, pela submissão por avaliadores em eventos, periódicos editais são condições de perseverança do grupo.

A isso o grupo persevera tomando por indicadores de critérios em Beillerot (2001, p.30): "a introdução de uma dimensão de crítica e de reflexão sobre suas fontes, seus métodos, seus modos de trabalho; uma sistematização da coleta dos dados; a presença de interpretações enunciadas segundo teorias reconhecidas e atuais que contribuam à elaboração de uma problemática e à interpretação dos dados".

Ressaltamos que a definição da problemática de pesquisa se apoia na compreensão de que a prática não é dirigida pela teoria, mas a teoria vai expressar a ação prática dos sujeitos. São as ações e modos de agir determinantes das formas de pensar dos homens. "A teoria pensa e compreende a prática sobre as coisas, não a coisa. Daí, a sua única função é indicar caminhos possíveis, nunca governar a prática." (BRUNO 1989, p. 18). O conhecimento toma por base a ação prática que os homens realizam por meio de relações sociais, instituídas. O pressuposto básico é que "o homem não reflete sobre o mundo, mas reflete a sua prática sobre o mundo" (BERNARDO, 1977, v. 1, p. 86). Deste modo, "(...) o conhecimento é sempre o conhecimento de uma prática, nunca da realidade natural ou social" (SANTOS 1992, p. 29, Apud MATINS; ROMANOWSKI, 2010, p. 208).

No campo da formação de professores quando do exame de seus elementos e componentes os estudos e indicações de Roldão (2007) sobre a constituição do campo disciplinar da formação de professores como "campos estruturantes", "campos adjacentes" e "campos próximos", e também os estudos de Marcelo (1999, 2009), André (2010).

As pesquisas sobre a formação inicial consideram as pesquisas sobre a conjuntura desta formação realizadas por inúmeros autores como Gatti e Barreto (2009); Diniz-Pereira (2000); Diniz-Pereira, J. E. E Viana, G. M. (2010); Terrazan (2008); Gatti (2010); Scheibe (2010); Nóvoa (1992, 1995).

Nos estudos sobre formação continuada, a estes autores se somam Imbernón (2000, 2009, 2010); Gatti, Barreto e André (2011) ao considerar como um processo contínuo em que se articula o desenvolvimento profissional docente e a prática pedagógica. Os contributos da formação continuada assumem um espectro ampliado: a possibilidade de aprofundamento dos conhecimentos para a docência, conhecimentos das áreas a ensinar, conhecimentos do ensinar - relação conteúdo e forma, finalidade e resultados, conhecimentos sobre a política educacional, o contexto educacional, sobre a escola, os alunos e a aprendizagem. Além disso, a formação continuada, potencialmente, proporciona compreender melhor as práticas pedagógicas, elevação do estatuto de profissionalização docente, legitimação da identidade profissional, consciência de si, de seu trabalho e de sua condição profissional. Contraditoriamente, a formação continuada restringe-se a eventos pontuais, inclui de modo parcimonioso a reflexão da prática e a coletividade profissional, permanecendo como possibilidade e não em efetividade, o que exige a sua problematização. Com efeito, programas contínuos de longa duração para uma definição de políticas de formação se diluem a cada governo e gestão institucional, como por exemplo, PIBID, PARFOR, PNAIC, entre outros.

Nas pesquisas sobre desenvolvimento profissional os referenciais envolvem desde a conceituação: Marcelo (2009); Vaillant e Marcelo (2012); Romanowski e Martins (2010) em que se examinam os efeitos do desenvolvimento sobre os professores, a relação entre as reformas educacionais e o desenvolvimento docente. Ainda, abrange a relação entre a profissão docente e a pessoa do professor (JOSSO, 2004; DAY, 2001). O grupo insere nesta temática os processos de inserção profissional, sobre este processo foram realizadas pesquisa 


\section{autêntica}

DOI https://doi.org/10.31639/rbpfp.v10i18.178

que se articulam com o Congresso Internacional sobre Professorado Principiante e Inserção Profissional à Docência, desde o Chile (2012) à República Domenicana (2016). As investigações dialogam com aportes que se constituem nos debates sobre essa problemática Huberman (1992); André (2012); Marcelo (2009); Cunha (2016); Gariglio (2016); Romanowski e Martins (2013); Romanowski (2010). Em relação ao ingresso na profissão, cabe destacar que as iniciativas de apoio, acompanhamento e desenvolvimento, são incipientes nas mantenedoras e instituição de ensino no Brasil, o que impulsiona a realização de estudos para colocar em pauta programas e políticas de acolhimento e inserção profissional dos professores.

Ainda, que de maneira pontual, destacamos os aportes em relação às pesquisas no campo da didática: Candau (1988); Martins (2009, 2008a, 2008b); Veiga (2012); Wachowicz (2001); Marin (2005). Como ressaltado em Martins (2009) o processo de ligação entre a didática e a formação de professores resulta da vivência de um processo de investigação de ação-reflexão-ação. Entende que a Didática prática acontece nas salas de aula onde se manifesta. É a partir desta prática que a pesquisa a problematiza para explicar e compreender os seus determinantes, permitindo a elaboração de propostas concretas de ação e concomitante se constitui como objeto de estudo e investigação, de onde se produz a teoria como expressão da prática.

As pesquisas sobre as tecnologias educacionais e a formação de professores observam e tomam por base os estudos que consideram o processo de aprendizagem do professor para a integração curricular das tecnologias a partir dos estudos sobre os níveis de integração definidos por Moersch $(1995,1997,2002,2010)$ e da proposta de integração curricular apresentada por Almeida e Valente (2011), complementando os estudo da integração curricular das tecnologias com autores específicos do campo de formação de professores (ROLDÃO, 2007), da didática (MARTINS, 2012) e ainda da mudança educacional (FULLAN, 2009) considerando que os estudos sobre a integração das tecnologias digitais ao contexto escolar não devam ter o foco em si mesmos e sim perpassar todos os campos de estudos educacionais.

A estes temas de estudo estão somadas pesquisas do tipo estado da arte e de revisões sistemáticas, que situam o objeto investigado no conjunto das produções científicas. As pesquisas nesta perspectiva podem vir a ser modalidade de estudo dependendo da abrangência e protocolo de metodologia adotado. Os estados da arte do grupo tomam como ponto de partida situação de problemática para orientar a pesquisa. Nestes estudos, o processo se assemelha a revisões sistemáticas (ROMANOWSKI e ENS, 2006; VOSGERAU e ROMANOWSKI, 2012; ROMANOWSKI, 2012 ).

Entre os projetos principais situa-se o Projeto "Cenários Pedagógicos para a Integração das TICS na Formação de Professores - Cri@tividade", destacamos a necessidade de não sobrecarregar o professor-aluno com atividades a serem realizadas a distância; outro ponto a refletir é a relação entre o esforço-tempo empreendido e o retorno na carreira funcional do professor. Estas e outras observações levam a inferir que, para que ocorra um processo de formação em serviço, são necessárias mudanças político-administrativas nos planos de carreira docente.

Um segundo projeto aborda a Interlocução da prática pedagógica da educação básica com a universidade no processo de formação docente. Este projeto tem como objeto de estudo a prática pedagógica de profissionais da educação das diferentes modalidades e ensino (Educação Infantil, Ensino Fundamental e Médio, Ensino Superior) e toma como referência as atuais políticas de inclusão e diversidade na busca da equidade social. O objetivo da investigação é sistematizar, a partir das iniciativas dos profissionais da educação de diferentes instituições, princípios orientadores para a prática pedagógica como expressão das relações sociais desse momento histórico, tendo em vista contribuir com a interlocução entre os cursos de formação 


\section{autêntica}

DOI https://doi.org/10.31639/rbpfp.v10i18.178

de professores e a escola básica. O campo de investigação inclui diferentes instituições onde o processo educativo é realizado tais como: comunidades Quilombola, educação em unidades penais na perspectiva dos Direitos Humanos; escolas da Rede Municipal de Ensino de Curitiba e outras escolas. A partir desse projeto foi realizado um Curso de Extensão Universitária denominado "Análise crítica e reformulação da prática pedagógica", numa abordagem de pesquisa-ensino (MARTINS, 2016) que tem em vista levar uma contribuição aos sujeitos envolvidos na pesquisa, durante a realização da mesma. O impacto social esperado com os resultados do estudo é contribuir com os avanços na prática pedagógica para a transformação do processo educativo e para o conjunto das pesquisas da área.

Ainda, integra o grupo o projeto Inserção Profissional do Professor da Educação Básica: da formação do professor à profissionalização. Este projeto focaliza a profissionalização docente, da inserção à consolidação da carreira de professor. Tem por objetivos: compreender o processo de inserção profissional do professor desde as primeiras iniciativas nas proposições de sistematização da prática docente, indicando rupturas e mudanças na conquista da profissão e analisar o processo de continuidade da formação na direção da profissionalização. Resultados deste projeto têm sido amplamente divulgados e se reportam às possibilidades em relação a possíveis melhorias do processo de inserção profissional de professores principiantes no Brasil, expressando-se nos seguintes aspectos: (i) realização de pesquisas sobre a questão; (ii) criação de programas de apoio e acompanhamento de professores principiantes; (iii) inclusão da inserção profissional nas políticas educacionais.

Os programas direcionados à inserção profissional como modo de formação e apoio aos professores iniciantes começam a ganhar destaque nas secretarias de educação e em algumas universidades. Em algumas secretarias de educação são ofertados palestras e cursos introdutórios de curta duração, com a finalidade de favorecer a compreensão das políticas educacionais desenvolvidas naquele município e ou estado; contudo, esta oferta não é regular e não se estende a todos os locais. De modo geral, a oferta está condicionada à urgência para o atendimento de turmas sem professores. Nos estados e municípios que realizam contratos temporários, esses cursos são ofertados apenas para professores concursados. Assim, a inserção do professor é realizada pela equipe pedagógica da escola. Ainda, é comum os professores iniciantes assumirem as turmas com alguma situação de dificuldade, o que amplia os desafios da iniciação profissional.

Estão em discussão no grupo dois novos projeto de pesquisa: um direcionado para os processos de formação de professores e outro que busca compreender as relações entre a didática e a formação docente.

Aos projetos se integram pesquisas de estudantes de graduação (PIBIC) mestrandos e doutorandos que ampliam e aprofundam assuntos relacionados às questões orientadoras das pesquisas. As discussões realizadas no grupo permitem a compreensão do campo da formação de professores e desenvolvimento profissional no atual contexto sócio-histórico. Nesse sentido, a pouca atratividade dos cursos de licenciatura, os processos de reformulações desses cursos sem que fortaleçam a formação efetiva dos professores, a constante desvalorização docente acentuada pelas políticas públicas descompromissadas com a carreira como prioridade para a profissionalização dos professores, os programas de formação continuada descontínuos e focados na produção de resultados, apontam para um contexto de questões complexas neste campo.

Entre as publicações recentes do grupo (artigos em periódicos e capítulos de livros), cabe destacar: as discussões sobre as prioridades nos processos de formação inicial e continuada; a compreensão do desenvolvimento profissional do professor; a inserção profissional do professor nos sistemas de ensino; o campo da didática na formação dos professores; e os estudos de revisão sistemática. 


\section{autêntica}

Para finalizar este item do texto cabe ressaltar que o levantamento de dados considera a escola como espaço privilegiado para a realização da coleta. A coleta de dados adota como critério a problematização e os objetivos da pesquisa para direcionar a escolha e definição dos instrumentos, técnicas e procedimentos. Assim, questionários, entrevistas, grupo focal, observações, história de vida, cada um deles ou combinados entre si podem ser empregados. Do mesmo modo, a análise de documentos pode ser somada às demais técnicas favorecendo um espectro denso de dados da realidade escolar. As pesquisas podem obter dados junto aos estudantes, professores, membros de grupos de gestão, professores formadores. Estes estão entre os sujeitos participantes nas investigações.

Quanto a composição das pesquisas, as indicações de Weller e Pfaff (2010), Gatti e André (2010), Gamboa (2012) constituem-se os aportes metodológicos que carecem ser considerados. Esta perspectiva, esclarecem Gatti e André (2010, p. 29) os estudos sobre o humano-social, o humano educacional solicitam "um mergulho em interações situacionais." Assim, é possível interpretar e compreender aproximando-se do real coerente com as formas humanas de agir, pensar, expressar, etc. Com efeito, para compreender um fenômeno em estudo é preciso ir além da sua manifestação aparente, considerando sua especificidade, as relações e as contradições que o produzem, sempre em movimento e constituídas na prática social conforme Triviños (1987).

\section{ARTICULAÇÃO COM OUTROS GRUPOS DE PESQUISA}

Além das pesquisas inter-relacionadas aos projetos explicitados anteriormente neste texto, considera-se pertinente abordar as articulações com outros grupos de pesquisa em formação de professores. Mantém vinculação com a ANPED, nos Grupos de Trabalho - Didática e Formação de Professores - GT04 e GT08, respectivamente.

O Grupo Práxis Educativa: Dimensões e Processos integra a Rede Interinstitucional de Pesquisadores em Formação de Professores e Prática Docente - RIPEFOR. Esta rede é integrada por pesquisadores de nove instituições que tem por objeto de estudo a prática pedagógica e a formação de professores. Sistematicamente, a rede realiza seminários de pesquisa em que são socializados e discutidos os projetos de investigação. Em 2016, foi publicado livro oriundo das pesquisas de seus membros, Práticas de formação de professores: da educação básica à educação superior (2016).

Ainda, na perspectiva internacional, o grupo participa da Red de Indución a la Docência, coordenada por Marcelo Garcia, principalmente com participação nos eventos do Congresso de Professores Principiantes (CONGREPRINCI), com possibilidades de integrar pesquisa sobre a educação informal e a formação de professores. O grupo também participa da ISATT International Study Association on Teachers and Teaching, com publicações em seus eventos.

Recentemente, o grupo tem sua participação com o Centre de recherche interuniversitaire sur la formation et la profession enseignante (CRIFPE) Canadá, e está em fase de proposição de pesquisa 


\section{autêntica}

DOI https://doi.org/10.31639/rbpfp.v10i18.178

\section{CONSIDERAÇÕES FINAIS}

Os grupos de pesquisa começaram a aparecer no Brasil no inicio da década de 1970, mas poucos estabelecem pesquisas abrangentes e de longa duração, pois falta condições aos docentes para se dedicarem aos trabalhos de pesquisa nas universidades (ANDRÉ, 2010 ).

$\mathrm{Na}$ atualidade as políticas públicas buscam estimular a permanência de grupo de pesquisa "para garantir a continuidade dos mesmos e favorecer a capacitação de novos pesquisadores" (GATTI, 2017, p. 161). Em décadas anteriores, mesmo com a existência de grupos de pesquisa, o registro de pesquisas coletivas era insipiente, pois a maioria das pesquisas na área de educação era oriunda de dissertações de mestrado e teses de doutorado (GATTI, 2017). Destaca a autora que a realização de pesquisas para intercâmbios interinstitucionais empreendidas a partir dos anos de 1990, permitiu a sua consolidação como produtores de pesquisa de modo mais aprofundado e com cuidados teóricos e metodológicos.

Ressaltamos que estudos sobre grupos de pesquisa são ainda restritos. Esse fato expressa a importância dos simpósios de grupos de pesquisa como os realizados pelo GT Formação de Professores da ANPED. A iniciativa do GT em publicar artigos sobre os grupos de pesquisa poderão contribuir para: (i) a difusão dos grupos divulgando sua organização, trajetória e linhas metodológicas; (ii) promover o debate em torno das questões que permeiam a pesquisa sobre formação de professores; (iv) favorecer as discussões em torno das possibilidades metodológicas da pesquisa em formação de professores; (v) apontar os assuntos e temáticas abordadas permitindo indicações dos contornos do campo de pesquisa em formação de professores.

Finalizando destacamos que a contribuição do grupo se expressa na formação continuada de professores e na formação de pesquisadores. Contribui igualmente com a produção científica pelas pesquisas realizadas, tanto nas dissertações de mestrado e teses de doutorado, e com as pesquisas financiadas pelos órgãos de fomento. Mantém uma publicação intensa de artigos científicos em periódicos nacionais e internacionais, capítulo de livros, livros organizados, trabalhos em eventos como comunicações, participação em mesas, simpósios e em palestras proferidas.

O Grupo Práxis ao focalizar os campos Didática, Formação de Professores e Tecnologias, busca manter o diálogo desses campos considerando as especificidades de cada um deles. Entende que a pesquisa traz contribuições para a compreensão da prática por meio do exame rigoroso dos determinantes que a expressam tomando a teoria como ferramenta poderosa, tendo a prática social como ponto de partida a qual após problematizada, explicada e compreendida nos seus determinantes mais profundos, resulte na sistematização de conhecimentos que expressem as relações sociais que os determinam e são determinados por ela, tendo em vista a sua transformação. Trata-se de um movimento dialético em que se constrói e se reconstrói a teoria, para retornar à prática. 


\section{autêntica}

DOI https://doi.org/10.31639/rbpfp.v10i18.178

\section{REFERENCIAS}

ALMEIDA, M. E. B. de; VALENTE, J. A. Tecnologias e Currículo: trajetórias convergentes ou divergentes? São Paulo: Paulus, 2011.

ANDRÉ, M. E. D. A. Formação de professores: a constituição de um campo de estudos. Educação. Porto Alegre, PUC/ RS, v. 33, p. 6-18, 2010.

ANDRE, M. Políticas e programas de apoio aos professores iniciantes no Brasil. Cad. Pesqui. [online]. 2012, vol.42, n.145, pp.112-129. ISSN 0100-1574. http://dx.doi.org/10.1590/S0100-15742012000100008.

BARDIN, L. Análise de Conteúdo. 3 reimp. São Paulo: Edições 70, 2010.

BEILLEROT, J. A pesquisa: esboço de uma análise. In: André, Marli (org). O papel da pesquisa na formação e prática dos professores. Campinas, SP: Papirus, 2001

BERNARDO, J. Marx crítico de Marx. Porto, Editora Afrontamento, 1977.

BRUNO, L. Acerca do indivíduo, da prática e da consciência da prática. Educação \& Sociedade, São Paulo, v. 33, pp. 7-26, ago., 1989.

CANDAU, V. Rumo a uma nova didática. Petrópolis: Vozes, 1988.

COSTA, M. C. V.. Pesquisa em educação: concepções de ciência, paradigmas teóricos e produção de conhecimentos. Cad. Pesqui., São Paulo, n. 90, ago. 1994. Disponível em <http://educa.fcc.org.br/scielo. php?script=sci_arttext\&pid=S0100-15741994000300002\&lng=pt\&nrm=iso>. acessos em 09 nov. 2017.

CUNHA, M. I.da. Pesquisa e pós-graduação em Educação: O sentido político e pedagógico da formação. In: SILVA, Alex Sander; SILVA, IIton Benoni da; ORTIGARA, Vidalcir. (Org.). Educação, Pesquisa e Produção do Conhecimento. Abordagens Contemporâneas. 1ed.Criciuma: EdilNESP, 2014, v. 1, p. 61-77.

CUNHA, M. I. da. Aprendizagem da docencia em espaços institucionais: é possível fazer avançar o campo da formação de professores?. In: Marielda Ferreira Pryjma e Oseias Santos de Oliveira. (Org.). O desenvolvimento profissional docente em discussão.. 1ed.Curitiba: Editora da UTFPr, 2016, v. 1, p. 63-78.

DAY, Christopher. Desenvolvimento Profissional de professores. Os desafios da aprendizagem permanente Porto: Porto Editora, 2001.

DINIZ-PEREIRA, J. E. and VIANA, G. M. (2010). A atual reforma das licenciaturas na UFMG e as lutas concorrenciais no campo universitário. In: Simone Albuquerque da Rocha. (Org.). Formação de professores: licenciaturas em discussão. Cuiabá, M. G.: EdUFMT, 1, 15-24.

DINIZ-PEREIRA, J. E. Formação de professores: pesquisas, representações e poder. Belo Horizonte: Autêntica, 2000.

FULLAN, M. O significado da mudança educacional. Porto Alegre: Artmed, 2009.

GARIGLIO, J. A. A inserção profissional de professores de educação física iniciantes: aprendendo a ser professor. Educação (PUCRS. Impresso), v. 39, p. 312, 2016.

GATTI, B. A., Política de Ciência e Tecnologia e Pesquisa em Educação. Revista Eletrônica de Educação, v.11, n.1, p.151-164, jan./maio, 2017. Artigo. ISSN 1982-7199 | DOI: http://dx.doi.org/10.14244/198271992084. 


\section{autêntica}

DOI https://doi.org/10.31639/rbpfp.v10i18.178

GATTI, B. A., BARRETO, E. S. DE S. Professores do Brasil. Brasília: UNESCO, 2009.

GATTI, B. A.; BARRETO, E. S. S.; ANDRE, M. E. D. A. Políticas docentes no Brasil: um estado da arte. Brasília, DF: UNESCO, 2011.

GATTI, B.; ANDRÉ, M.. A relevância dos métodos de pesquisa qualitativa em Educação no Brasil. In: WELLER, W.; PFAFF, N. (Orgs.). Metodologias da pesquisa qualitativa em educação: teoria e prática. Petrópolis: Vozes, 2010.

GATTI, B. A.. Formação de professores no Brasil: características e problemas. Educ. Soc. [online]. 2010, vol.31, n.113, pp.1355-1379. http://dx.doi.org/10.1590/S0101-73302010000400016.

HUBERMAN, M.. O ciclo de vida profissional dos professores. In: NÓVOA, Antônio. Vidas de Professores. Porto: Porto Editora, 1992.

IMBERNON, F. Formação docente e profissional: formar-se para a mudança e a incerteza. 7. Ed. São Paulo: Cortez, 2009.

IMBERNÓN, F.. Formação continuada de professores. Porto Alegre: Artmed, 2010.

JOSSO, M.C. Experiências de vida e formação. 2ª edição. Natal, RN: EDUFRN; São Paulo: Paulus, 2010.

MARCELO C. G. Formação de professores - Para uma mudança educativa. Portugal: Porto Editora, 1999.

MARCELO, C. G. El professorado principiante. Inserción a la docência. Barcelona. Ediciones Octaedro, 2009. MARIN, A. J.. Didática e trabalho Docente. 2a. ed. Araraquara: JM Editora, 2005. v. 1. 140p .

MARIN, A. J.; PENNA, M. G. O.; RODRIGUES, A. C. C.. A Didática e a formação de professores. Revista Diálogo Educacional, Curitiba, v. 12, n. 35, p. 51-77, jan./abr. 2012. MARTINS, P. L. O.. A didática e as contradições da prática.. 3. ed. Campinas -SP: Papirus, 2009.

MARTINS, P. L. O.. Didática teórica/Didática prática: para além do confronto.. 9. ed. São Paulo: Edições Loyola, 2008. v. 1. 184p .MARTINS, P. L. O.. Didática. 1. ed. Curitiba: Editora IBPEX, 2008. v. 1. 84p .

MARTINS, P. L. O.. Pesquisa-ensino na formação inicial de professores e a interlocução com a educação Básica: princípios e metodologia. In: ROMANOWSKI, J. P.; MARTINS, P. L. O., CARTAXO, S. R. M.. (Org.). Práticas de formação de professores: da Educação Básica à Educação Superior. 1ed.Curitiba: Champagnat, 2016, v. 1, p. 01-20.

MARTINS, P. L.O. and ROMANOWSKI, J. P. A didática na formação pedagógica de professores nas novas propostas para os cursos de licenciatura. In: Angela Dalben; Júlio Diniz; Leiva Leal; Lucíola Santos. (Org.). Convergências e tensões no campo da formação e do trabalho docente: didática, formação de professores e trabalho docente. Belo Horizonte: Autêntica, (1), 60-80, 2010.

MESSINA, G. Estudio sobre el estado da arte de la investigacion acerca de la formación docente en los noventa. Revista Iberoamericana de Educación n. 19, Formación Docente, Enero - Abril 1999 Disponível em: <http://rieoei.org/historico/oeivirt/rie19a04.html> Consulta em 10 set 2016.

MOERSCH, C.. Beyond hardware: Using existing technology to promote higher-level thinking. Washington DC: ISTE, 2002. 


\section{autêntica}

Dol https://doi.org/10.31639/rbpfp.v10i18.178

MOERSCH, C.. Computer Efficiency: Measuring the instructional use of technology. Learning and Leading with Technology, ISTE - International Society for Technology in Education, v. 24, n. 4, p. 52-56, dez/jan. 1996-97. Disponível em: <http://www.loticonnection.com/pdf/CompEfficiencyDec96.pdf>. Acesso em: 29 set. 2008.

MOERSCH, C.. Learning \& Leading with Technology, v37 n5 p20-23 Feb, 2010.

MOERSCH, C.. Levels of Technology Implementation: A Framework for Measuring Classroom Technology Use. Learning and Leading with Technology, ISTE - International Society for Technology in Education, v. 23, n. 3, p. 40-42, nov. 1995. Disponível em: <http://www.loticonnection.com/pdf/LoTiFrameworkNov95.pdf>. Acesso em: 29 set. 2008.

NÓVOA, A. Profissão Professor.Porto: Porto Editora, 1995.

NÓVOA, A., (coord.) Os professores e a sua formação. Lisboa : Dom Quixote,1992.

ROLDÃO, M. do C. Função docente: natureza e construção do conhecimento profissional. Revista Brasileira de Educação, 12(34), 94-103, 2007. https://dx.doi.org/10.1590/S1413-24782007000100008

ROMANOWSKI, J. P.; ENS, R. T. As pesquisas denominadas do tipo "Estado da Arte". Diálogos Educacionais, v. 6, n. 6, p. 37-50, 2006.

ROMANOWSKI, J. P. e MARTINS, P. L. O. Desafios da Formação de Professores Iniciantes.. Páginas de Educación. , v.6, p.83 - 96, 2013.

ROMANOWSKI, J. P.. Apontamentos em pesquisas sobre formação de professores: contribuições para o debate. Diálogo Educacional (PUCPR. Impresso). , v.12, 905, 2012.

ROMANOWSKI, J. P.. Formação e profissionalização docente. Ed 4. Curitiba: Editora IBPEX, 2010.

SALDAÑA, J. The coding manual for qualitative researchers. Beverly Hills: Sage, 2013.

SÁNCHEZ GAMBOA, S. Pesquisa em Educação: métodos e epistemologias. Chapecó SC: Argos, 2012

SANTOS, O. J. Fundamentos sociológicos da educação. Dissertação (Pós-graduação lato sensu em Psicopedagogia) - Faculdade de Ciências Humanas, Universidade FUMEC, Belo Horizonte, 2005. p. 13-50.

SCHEIBE, L.. Valorização e formação dos professores para a educação básica: questões desafiadoras para um novo Plano Nacional de Educação. Educ. Soc. [online]. 2010, vol.31, n.112, pp.981-1000. ISSN 0101-7330. http://dx.doi.org/10.1590/S0101-73302010000300017.

TERRAZZAN, E. A.; DUTRA, E. F.; WINCH, P.G.; SILVA, A. A. Configurações curriculares em cursos de licenciatura e formação identitária de professores. Curitiba: Diálogo Educacional, 8 (23), 2008.

TRIVIÑOS, A. N. S. Introdução à pesquisa em ciências sociais: a pesquisa qualitativa em educação. São Paulo: Atlas, 1987.

VAILLANT, D. \& MARCELO, C. Ensinando a ensinar: as quatro etapas de uma aprendizagem. $1^{\text {a }}$. Ed. Curitiba: Ed. UTFPR, 2012.

VALENTE, J. A. Computadores e Conhecimento: representando a educação. $2^{a}$ Ed., Campinas, SP: UNICAMP (NIED), 1998. 


\section{autêntica}

DOI https://doi.org/10.31639/rbpfp.v10i18.178

VEIGA, I. P. A. (Org.). Lições de Didática. 5. ed. Campinas, SP: Papirus, 2012.

VOSGERAU, D. S. A. R.; ROMANOWSKI, J. P. . Estudos de revisão: implicações conceituais e metodológicas. Revista Diálogo Educacional (PUCPR. Impresso), v. 14, p. 165, 2014.

VOSGERAU, D. S. A. R.; POCRIFKA, D. H.; SIMONIAN, M. Associação entre a técnica de análise de conteúdo e os ciclos de codificação: possibilidades a partir do software ATLAS.ti. RISTI. 2016

VOSGERAU, D. S. R.; MEYER, P.; CONTRERAS, R. Análise de dados qualitativos nas pesquisas sobre formação de professores. Revista Diálogo Educacional (PUCPR. Impresso), v. 14, p. 165, 2017.

WACHOWICZ, L. A. O método dialético na Didática. 2 ed.Campinas: Papirus, 1991.

WELLER, W.; PFAFF, N. (Orgs.). Metodologias da pesquisa qualitativa em educação: teoria e prática. Petrópolis: Vozes, 2010

\section{PARTICIPANTES DO GRUPO}

Camile Gonçalves Hesket Cardoso;

Carlos Henrique Martins Torra Helvig;

Cristine Xavier;

Débora Cristina de Oliveira Vieira;

Elisângela Gonçalves Branco Gusi;

Fábio Francisco Cardoso;

Ivana Suski Vicentim:

Jean Paulo Bernardo Xavier;

Joanita do Rocio Artigas;

Juliana Boff A. Cruz;

Késia da Silva Linhares Lucena Azevedo;

Liliamar Hoça;

Lilian Costa Cartex;

Maria Cristina Kogut;

Maria Cristina Trois Dorneles Rau;

Marília Marques Mira; Marly Macedo;

Marilúcia Antonia de Resende;

Marina M. Mariotto Belotto

Mary Ogawa;

Neuci Schotten;

Patrícia Meyer;

Paulo Sergio Maniesi;

Priscila Ximenes Souza do Nascimento;

Rosangela Gasparim;

Sandra Mara de Lara;

Silvia Vasconcellos.

Simone Regina Manosso Cartaxo;

Sonia Maria Ribeiro. 